\title{
Genome sequencing and carrier testing: decisions on categorization and whether to disclose results of carrier testing
}

\author{
Patricia Himes, MS1, Tia L. Kauffman, MPH², Kristin R. Muessig, MS², Laura M. Amendola, MS³, \\ Jonathan S. Berg, MD, PhD", Michael O. Dorschner, PhD5, Marian Gilmore, MS1, \\ Deborah A. Nickerson, $\mathrm{PhD}^{6}$, Jacob A. Reiss, $\mathrm{MD}^{2}$, C. Sue Richards, PhD ${ }^{7}$, Alan F. Rope, MD ${ }^{8}$, \\ Dana K. Simpson, $\mathrm{MD}^{8}$, Benjamin S. Wilfond, $\mathrm{MD}^{9}$, Gail P. Jarvik, MD, PhD ${ }^{3,6}$ and \\ Katrina A.B. Goddard, PhD²
}

\begin{abstract}
Purpose: We investigated the use of genome sequencing for preconception carrier testing. Genome sequencing could identify one or more of thousands of X-linked or autosomal recessive conditions that could be disclosed during preconception or prenatal counseling. Therefore, a framework that helps both clinicians and patients understand the possible range of findings is needed to respect patient preferences by ensuring that information about only the desired types of genetic conditions are provided to a given patient.
\end{abstract}

Methods: We categorized gene-condition pairs into groups using a previously developed taxonomy of genetic conditions. Patients could elect to receive results from these categories. A Return of Results Committee (RORC) developed inclusion and exclusion criteria for each category.
Results: To date, the RORC has categorized 728 gene-condition pairs: 177 are categorized as life span-limiting, 406 are categorized as serious, 93 are categorized as mild, 41 are categorized as unpredictable, and 11 are categorized as adult-onset. An additional 64 genecondition pairs were excluded from reporting to patients or put on a watch list, generally because evidence that a gene and condition were associated was limited.

Conclusion: Categorization of gene-condition pairs using our taxonomy simplifies communication regarding patient preferences for carrier information from a genomic test.

Genet Med advance online publication 12 January 2017

Key Words: carrier testing; categorization of genetic conditions; genome sequencing; results disclosure; return of results

\section{INTRODUCTION}

Incorporating genome sequencing into the research environment and clinical care requires a better understanding of the risks and benefits in different clinical contexts, including preconception carrier screening. The purpose of preconception carrier screening is to provide information to families to assist with reproductive decision-making, including options for prenatal and pre-implantation genetic diagnosis and options for using donor gametes and adoption to reduce the likelihood of having a child with a genetic condition, or to assist with decisions about whether to have children. Preconception carrier screening could also help mitigate the impact of a disorder through earlier diagnosis and treatment. However, as with other novel genetic testing strategies, the technical ability to perform laboratory analyses has occurred at a faster rate than the evidence base for optimal integration of this information into health-care delivery.

In 2011, the National Human Genome Research Institute and the National Cancer Institute initiated the Clinical Sequencing Exploratory Research (CSER) consortium ${ }^{1}$ to support multidimensional research regarding the optimal uses and implementation of whole-genome and whole-exome sequencing. CSER is a national interdisciplinary consortium of projects for developing and sharing innovations and best practices for the integration of genomic sequencing into clinical care. As a part of the CSER consortium, the NextGen study has been investigating the use of genome sequencing for preconception carrier testing.

In current clinical practice, some extremely rare genetic conditions are tested with large ( 100 conditions) carrier testing panels. Although it is possible for a patient to review $\sim 100$

\footnotetext{
${ }^{1}$ Department of Medical Genetics, Kaiser Permanente Northwest, Portland, Oregon, USA; ${ }^{2}$ Center for Health Research, Kaiser Permanente Northwest, Portland, Oregon, USA; ${ }^{3}$ Department of Medicine, Division of Medical Genetics, University of Washington, Seattle, Washington, USA; ${ }^{4}$ Department of Genetics, University of North Carolina, Chapel Hill, North Carolina, USA; ${ }^{5}$ Department of Pathology, University of Washington, Seattle, Washington, USA; ${ }^{6}$ Department of Genome Sciences, University of Washington, Seattle, Washington, USA; ${ }^{7}$ Department of Molecular and Medical Genetics, Oregon Health \& Science University, Portland, Oregon, USA; ${ }^{8}$ Northwest Permanente, Kaiser Permanente Northwest, Portland, Oregon, USA; ${ }^{9}$ Seattle Children's Research Institute, Treuman Katz Center for Pediatric Bioethics, Seattle, Washington, USA.

Correspondence: Katrina A.B. Goddard (katrina.ab.goddard@kpchr.org)
} 


\section{ORIGINAL RESEARCH ARTICLE}

conditions from current carrier panel screening, there are nearly $3,000^{2} \mathrm{X}$-linked and autosomal recessive conditions that could potentially be disclosed during preconception or prenatal counseling. A framework that helps both clinicians and future patients seeking preconception carrier screening to understand the possible range of findings is needed. Interestingly, there is little research on the types of carrier information that couples are interested in learning about, the psychological implications for couples at risk for having a child with these conditions, and the practical demands on the health-care delivery system. Expanding the scope of results from current carrier panels to genome-scale sequencing will provide further information for reproductive planning, but it excludes the possibility of a meaningful discussion of each gene-condition pair being evaluated.

By grouping disorders into categories, ${ }^{3}$ we developed a taxonomy framework that enables patients to decide what information they want. As part of the development of the taxonomy, we obtained feedback on initial drafts of the taxonomy from women in focus groups who previously underwent carrier testing for reproductive decision making. A key recommendation strongly expressed by all participants was the importance of providing choice at every level of offering genomic carrier screening-including the type and quantity of results being shared. They also supported assumptions that disease severity and age at onset are important factors, and that "shortened life span" is a discrete category of its own. Variability of a disorder was a less critical criterion for categorization and, in the case of a range of phenotypes, the most severe should be used. ${ }^{4}$ This focus group feedback, in conjunction with edits from the NextGen study personnel, led to final taxonomy categories of lifespan limiting, serious, mild, unpredictable, and adultonset. ${ }^{3,5}$ This taxonomy was validated in another population of reproductive-age women who had carrier testing performed. ${ }^{4}$

The concept of "binning" genetic conditions was proposed by Berg et $\mathrm{al}^{6}{ }^{6}$ and was first described for incidental findings for patients who undergo genome or exome sequencing. By selecting disclosure of information relevant to patients, a category-based approach facilitates informed consent and patient education and support. We adapted this approach to preconception carrier testing $g^{3,5}$ and have categorized relevant genedisorder pairs with this taxonomy.

Here, we describe the experience of the CSER/NextGen study regarding: (i) deciding which gene-condition pairs will be disclosed for preconception carrier screening and (ii) categorizing the gene-condition pairs into our taxonomy of genetic conditions. We present the categories in which the gene-condition pairs were placed. In addition, we discuss the challenges and lessons learned during this process.

\section{MATERIALS AND METHODS}

We convened a panel of experts, called the Return of Results Committee (the RORC), to determine reportable results for carrier screening from a genome-scale test. The RORC comprises a diverse group of experts in genetics and public health, including medical geneticists with metabolic, pediatric, and internal medicine expertise; genetic counselors; molecular laboratory directors and $\mathrm{PhD}$ geneticists; a perinatologist; a medical ethicist; and a genetic epidemiologist. The committee is chaired by a board-certified medical geneticist. The specific tasks of the RORC included:

1. Creating a list of gene-condition pairs for consideration of disclosure of carrier status

2. Determining which gene-condition pairs should be disclosed to participants

3. Categorizing the gene-condition pairs into a previously established taxonomy of genetic conditions: lifespan limiting, serious, mild, unpredictable, and adult-onset.

\section{Sources of gene-condition pairs}

The initial list of candidate genes associated with autosomal recessive and $\mathrm{X}$-linked conditions included those genes for which national professional organizations, including the American College of Medical Genetics and Genomics and the American Congress of Obstetricians and Gynecologists, recommended screening in at least one population, genes present on carrier tests from commercial laboratories that offered expanded carrier testing in 2013, genes associated with conditions that are commonly found on newborn screening panels, and genes associated with serious childhood recessive diseases. ${ }^{7}$ The list was then augmented by nominations from RORC members, such as genes associated with conditions with $\mathrm{X}$-linked inheritance, genes associated with the most common indications for referral to a clinical genetics department, mitochondrial genes (to ensure consideration of conditions with unpredictable outcome), and other genes associated with phenotypes already included on the list, such as genes associated with Leigh syndrome, sensory neural hearing loss, retinitis pigmentosa, and Usher syndrome.

\section{Development and application of inclusion and exclusion criteria for gene-condition pairs to be offered to participants}

Using published recommendations by professional organizations as a guide, ${ }^{8-15}$ the RORC developed criteria for deciding whether to disclose to patients certain results from carrier screening. These criteria emphasize return of clinically valid gene-disease-associated pairs (Table 1). So that CSER/NextGen would be able to better understand the benefits and risks of using genome sequencing for preconception carrier screening for patients, health-care providers, and health-care systems, we were intentionally broadly inclusive of the gene-condition pairs to be offered to participants within this framework.

The RORC reviewed the nominated genes to decide which gene-condition pairs met the proposed criteria. Each genecondition pair was initially reviewed by one of the study genetic counselors, who summarized the available evidence (including the clinical characteristics, associated mortality, and genotype-phenotype correlation). Given the large number of 
gene-condition pairs, the literature review was frequently limited by time constraints; sometimes committee members with particular expertise on a specific condition would conduct this preliminary review. In addition, outside experts in specific fields, especially metabolic disorders, were consulted. The evidence for each gene-condition pair was individually reviewed by each RORC member and augmented by the clinical experience of committee members. Unanimous agreement was required for a gene-condition pair to be included on the list.

Each gene-condition pair was assigned to an included, excluded, or watch category. Gene-condition pairs were excluded from the list when there was insufficient current evidence that variants in that gene are associated with disease. Pairs were excluded because of limited evidence, including disease association only from genome-wide association studies, isolated case reports in the literature, and genes identified in only a single family. Many excluded gene-condition pairs were placed on a watch list awaiting future data. Conditions associated with dominant inheritance were excluded except when homozygosity or compound heterozygosity was also known to be associated with a condition of interest, such as BRCA2 pathogenic variants and Fanconi anemia D1. New information will likely arise during the course of the CSER/NextGen study and alter the assignments to the included, excluded, and watch categories.

\section{Categorization of gene-condition pairs into taxonomy}

Our team previously reported the development and validation of a taxonomy of conditions for reporting carrier status: lifespan limiting, serious, mild, unpredictable, and adult-onset. ${ }^{4,5}$ Operational definitions for these categories are briefly summarized in Table 2. Evidence about each gene-condition pair was summarized by a member of RORC, who provided a preliminary assignment. After review of the summary description and based on the experience of RORC members, the final category was decided by the RORC. Because preconception identification implies that knowledge of the condition would be known prior to birth, we approached categorization from the premise that treatment would begin promptly for treatable conditions. As noted in Table 2, if treatment is not highly burdensome (e.g., X-linked ichthyosis), then a condition would be considered mild. If treatment is available but is still a major burden to families and the proband (e.g., phenylketonuria), then that condition would still be in the serious category.

Each condition was placed in only one category unless there were recognizable genotype-phenotype associations that could be distinguished based on genotype (i.e., different genes or different pathogenic variants in the same gene causing a different phenotype). In this case, each distinguishable form was placed in a separate category. For example, a common promotor region variant in the UGT1A1 gene is associated with Gilbert syndrome, which is typically characterized by benign

Table 1 Criteria for disclosing results for carrier screening

- Include genes associated with recessive or X-linked genetic disorders:

o When prenatal carrier screening is offered or

o That meet one or more of the following criteria in many people with a disorder that:

- Limits the lifespan

- Requires significant medical involvement and/or medical care cost

- Causes significant physical, cognitive, or sensory impairment

- Demands significant daily care and/or care cost to the family

- Is risky for the mother during pregnancy

- Can be treated to significantly mitigate or reverse symptoms

- Include genes associated with disorders that meet the aforementioned criteria for only some people with the disorder because of variable expressivity, incomplete penetrance, or mild phenotype. Results for these genes will be clearly identified.

- Exclude genes when there is insufficient evidence of pathogenicity.

- Exclude genes in which variants are associated with risk for disease.

- Exclude conditions associated with dominant inheritance except when homozygosity or compound heterozygosity is known to be associated with a specific phenotype.

Table 2 Taxonomy of conditions

Lifespan limiting (childhood): More than $50 \%$ a of patients die before age 10 and most die before age 30 .

Serious: Default category. A condition was placed in this category unless it appeared to have a better fit in one of the other categories. If there is variation in phenotype, then the majority of patients $(>50 \%$ a) have the most severe form.

Mild: Signs and symptoms of the condition are not typically life-threatening. Patients usually experience mild or moderate disruption to normal activities and functions (e.g., poor vision vs. blindness). If available, the treatment itself is not highly burdensome in terms of medical interventions or lifestyle modifications that are required. With treatment, patients may experience few or no symptoms.

Unpredictable: There is a wide range in the severity of the phenotype. Age at onset, severity of symptoms, or presence of symptoms may vary. The severity of the condition is unknown for a particular individual based on genotype. Fewer than half of patients have the most severe form.

Adult-onset: For approximately $75 \%$ a of patients, symptoms do not appear until after age 20.

aspecific percentages listed are meant as clarifiers to the descriptive words rather than thresholds. In many instances, the chances of certain events happening have not been precisely reported. 


\section{ORIGINAL RESEARCH ARTICLE}

hyperbilirubinemia; therefore, the UGT1A1-Gilbert syndrome pair was classified as mild. However, missense variants in this gene can be associated with Crigler-Najjar syndrome, which is characterized by hypotonia, intellectual disability, and death in childhood; therefore, the UGT1A1-Crigler-Najjar syndrome pair was classified as serious.

\section{RESULTS}

The RORC categorized a list of 728 gene-condition pairs (Table 3). A total of 177 were categorized as lifespan limiting, 406 were categorized as serious, 93 were categorized as mild, 41 were categorized as unpredictable, and 11 were categorized as adultonset. In addition, 64 gene-condition pairs were excluded or put on a watch list (Supplementary Tables S1-S6 online).

\section{Challenges faced by the Return of Results Committee}

Determining suitable categorizations for rare conditions with a limited number of case reports presented the greatest challenge for the RORC. Published literature often provided insufficient information on survival and the possible variability in expression in rare genetic conditions. In addition, the committee suspected that cases reported in the medical literature are biased toward more severe presentations; therefore, it was difficult to find data to accurately categorize such conditions as lifespan limiting or unpredictable. In this context, conditions were typically placed in the default category of serious. We anticipate that categorization of gene-condition pairs will evolve as additional information regarding clinical presentation becomes available and more cases that represent the mild end of the spectrum are observed. This assumption will need to be investigated in a population of ethnically diverse couples during both the preconception and prenatal time period.

Genes associated with a spectrum of clinical presentations have presented challenges, especially when there are no known genotype/phenotype correlations and phenotypic variability is reported within the same family. For example, pathogenic variants in the CEP290 gene have been found in individuals with Leber congenital amaurosis (associated with isolated vision loss) and in people with Meckel syndrome (usually a life spanlimiting condition associated with encephalocele and cystic dysplastic kidneys). In such cases, the committee ultimately elected to categorize the gene-condition pair in the lifespan

Table 3 Example conditions by category $(N=728)$

\begin{tabular}{|c|c|c|}
\hline Category & $n$ & Examples \\
\hline Lifespan limiting & 177 & $\begin{array}{l}\text { Krabbe disease (GALC), Tay-Sachs disease } \\
(\text { HEXA) }\end{array}$ \\
\hline Serious & 406 & $\begin{array}{l}\text { Duchenne muscular dystrophy (DMD), } \\
\text { Cystic fibrosis (CFTR) }\end{array}$ \\
\hline Mild & 93 & $\begin{array}{l}\text { Cystinuria type } \mathrm{A}(S L C 7 A 9) \\
\text { hereditary fructose intolerance (ALDOB) }\end{array}$ \\
\hline Unpredictable & 41 & $\begin{array}{l}\text { Gaucher disease (GBA), } \\
\text { Schindler disease I (NAGA) }\end{array}$ \\
\hline Adult-onset & 11 & $\begin{array}{l}\text { Hemochromatosis (HFE), } \\
\text { Alpha1 antitrypsin deficiency (SERPINA1) }\end{array}$ \\
\hline
\end{tabular}

limiting category because we expect that patients will be more likely to want results from the more severe end of the spectrum.

\section{DISCUSSION}

We identified specific criteria for selecting gene-condition pairs for disclosing carrier status, developed operational definitions for these criteria, and, to date, applied the criteria of 792 genecondition pairs to consideration by the RORC. By unanimous agreement of the committee, we identified 728 gene-condition pairs that met these criteria and 64 gene-condition pairs that did not. These findings may be useful to others interested in disclosing carrier status from genome or exome sequencing.

We modeled our approach on practices that have been developed elsewhere. Berg et al. ${ }^{16}$ described the procedures developed by six sites in the CSER consortium, including committees with expertise similar to our own. Most sites established an a priori list to decide which gene-condition pairs would be disclosed. Professional organizations and recommendations from other sources $^{8,17,18}$ suggest that decisions regarding what to disclose for carrier status should be based on set criteria rather than the inclusion of as many gene-condition pairs as possible. We have articulated clear criteria and operational definitions for making decisions about results disclosure.

The strength of our approach is that it enables patients to decide what kinds of results to receive from genome or exome sequencing without having to review all gene-condition pairs for which carrier status may be identified. The concepts of "binning" results and allowing participants to choose what kinds of results to receive from genome or exome sequencing are consistent with general practice. As Berg et al. ${ }^{6}$ noted, a binning system is scalable and directly involves a patient-driven approach to results disclosure by allowing individuals to opt in or out of certain categories ("bins") according to their preference.

There were multiple limitations to our approach. We did not include all possible recessive or X-linked conditions to make the process feasible, and we excluded gene-condition pairs with limited causal evidence. Some categorizations may change as more information accumulates, particularly for very rare conditions. In addition, we did not incorporate patient groups or the public in the process of classifying gene-condition pairs. Although patients were involved in the creation of the initial taxonomy, ${ }^{4,19}$ they were not involved in the RORC. It is possible that they may have had a different perspective when classifying some of the conditions, especially if they had personal experience with a condition. Finally, our criteria did not consider whether it is technically feasible to report findings for a particular gene by using a particular sequencing platform. For instance, the platform we use has low coverage for SMN1; therefore, we do not report findings for this gene, even though it is included in the category of lifespan limiting.

Our RORC and others continue to systematically collect information regarding participants' preferences about the types of results that patients want disclosed by giving them choices. ${ }^{4,5,16}$ In our own work validating the taxonomy with patients' perspectives, it is challenging to distinguish between 
the serious and mild categories because of the subjective nature of how serious a condition is. The operational definitions of the categories were created and validated based on the results of a survey with reproductive-age women who had undergone prior carrier testing. ${ }^{4,5}$ In discussions, the RORC itself frequently had a difficult time distinguishing between these categories. Wertz and Knoppers (2002) ${ }^{20}$ also previously discussed the inconsistency in how genetics professionals define the "seriousness" of conditions. In the future, we may collapse these categories. As other genetic factors that modulate the clinical presentation of "single-gene" disorders are identified, the process of categorizing conditions will become even more complicated.

Although the RORC members had a broad range of expertise and perspectives, we often relied on individual experience with and knowledge about conditions. Also, although the time to review and classify conditions was substantial, it was nevertheless limited for any given condition. Moving beyond these limitations will require broader community engagement. The ClinGen Consortium is one example that includes mechanisms for engaging both experts (e.g., clinicians, laboratorians, and researchers) and individual patients, supporting broad datasharing, and assembling platforms for curating evidence. ${ }^{21}$ Ultimately, a broad, community-based approach to categorization of gene-condition pairs for disclosing carrier status is needed to enable individual organizations to leverage the efforts by others, limit redundancy, and produce greater consistency in interpretation.

Several professional organizations have proposed types of carrier results that could be considered for disclosure. Edwards et al..$^{18}$ noted the importance of restricting carrier testing panels to conditions associated with cognitive disability, the need for surgical or medical intervention, the effect on quality of life, and the prenatal diagnosis that would alter prenatal or postnatal management. The American College of Medical Genetics and Genomics ${ }^{8}$ recommends restricting carrier testing to conditions that would be considered for reproductive decision making. Our own list includes numerous conditions for which prenatal testing is rarely requested, including genes associated with adult-onset conditions, unpredictable outcomes, and conditions such as hearing or vision loss that we included in our study to determine patient preferences. The National Society of Genetic Counselors ${ }^{22,23}$ articulated that prenatal testing for adult-onset disorders should be discouraged unless pregnancy management would be altered or clinical intervention would be initiated during childhood; this position reflects the desire to protect the autonomy of a future child.

RORC activities were conducted in the context of a research study, which differs from clinical care in both methods and goals. Therefore, the choices made for the purposes of the CSER/NextGen study should not be interpreted as recommendations for clinical care. ${ }^{24}$ The list included genes associated with very rare conditions, for which the detection rate, carrier frequency, and breadth of clinical presentations are poorly understood. There is the possibility of increasing anxiety associated with these sorts of results. An overarching purpose of the CSER/NextGen study was to explore the types of information that could be disclosed to patients for carrier status or that might be desired by individuals. To assess individuals' boundaries, we created a broad and inclusive scope for disclosure. As yet, there is no agreement in the patient or provider communities regarding how or whether carrier screening should be expanded. However, Lazarin et al..$^{25}$ recently conducted a survey with genetic counselors that indicated general agreement with expanded carrier screening: only $27 \%$ agreed that carrier screening should be limited to conditions recommended in current guidelines for general population screening and $80 \%$ of the respondents preferred to be tested for a larger number of disorders themselves if the financial costs were the same. ${ }^{25}$

We previously published a taxonomy for binning of carrier gene-condition pairs to be offered to patients wanting reports of genome-scale carrier status. Now, we have reported the categorization of such gene-condition pairs in our taxonomy. Our approach used a diverse array of methods and stakeholder opinions to create an initial categorization schema for the return of genome-scale sequencing, including reviewing existing literature, obtaining expert opinion, and conducting patient surveys and focus groups. This method of classifying gene-condition pairs will allow patients to make choices within a simplified framework. Additional work is now needed to evaluate these categories in practice, allowing for refinement and adjustment as needed based on more patient and provider feedback. Future work can also seek to understand the benefits and risks from the individual and societal perspectives on disclosing carrier status beyond the current guidelines for sequencing.

\section{SUPPLEMENTARY MATERIAL}

Supplementary material is linked to the online version of the paper at http://www.nature.com/gim

\section{ACKNOWLEDGMENTS}

This work was supported by a grant from the National Human Genome Research Institute (UM1HG007292; co-PIs: Wilfond, Goddard), with additional support from the Coordinating Center (U01HG007307; PI: Jarvik) and the NextMed Study (U01HG006375; PI: Jarvik) as part of the Clinical Sequencing Exploratory Research (CSER) consortium. The authors thank the other members of the study team, including Cary Harding, for their many useful insights and discussions about the study.

\section{DISCLOSURE}

The authors declare no conflict of interest.

\section{REFERENCES}

1. Green RC, Goddard KA, Jarvik GP, et al.; CSER Consortium. Clinical Sequencing Exploratory Research Consortium: accelerating evidence-based practice of genomic medicine. Am J Hum Genet 2016;98:1051-1066.

2. McKusick-Nathans Institute of Genetic Medicine Johns Hopkins University. Online Mendelian Inheritance in Man, OMIM. 2016. http://omim.org/. Accessed 03 March 2016.

3. Wilfond BS, Goddard KA. It's complicated: criteria for policy decisions for the clinical integration of genome-scale sequencing for reproductive decision making. Mol Genet Genomic Med 2015;3:239-242. 


\section{ORIGINAL RESEARCH ARTICLE}

4. Leo MC, McMullen C, Wilfond BS, et al. Patients' ratings of genetic conditions validate a taxonomy to simplify decisions about preconception carrier screening via genome sequencing. Am J Med Genet A 2016;170: 574-582.

5. Korngiebel DM, McMullen CK, Amendola LM, et al. Generating a taxonomy for genetic conditions relevant to reproductive planning. Am J Med Genet $A$ 2016;170:565-573

6. Berg JS, Khoury MJ, Evans JP. Deploying whole genome sequencing in clinical practice and public health: meeting the challenge one bin at a time. Genet Med 2011;13:499-504

7. Bell CJ, Dinwiddie DL, Miller NA, et al. Carrier testing for severe childhood recessive diseases by next-generation sequencing. Sci Trans/ Med 2011;3:65ra64.

8. Grody WW, Thompson BH, Gregg AR, et al. ACMG position statement on prenatal/preconception expanded carrier screening. Genet Med 2013;15: 482-483.

9. Sherman S, Pletcher BA, Driscoll DA. Fragile X syndrome: diagnostic and carrier testing. Genet Med 2005;7:584-587.

10. Brandt DS, Shinkunas L, Hillis SL, et al. A closer look at the recommended criteria for disclosing genetic results: perspectives of medical genetic specialists, genomic researchers, and institutional review board chairs. J Genet Couns 2013:22:544-553.

11. Bredenoord AL, Onland-Moret NC, Van Delden JJ. Feedback of individual genetic results to research participants: in favor of a qualified disclosure policy. Hum Mutat 2011;32:861-867.

12. Prior TW; Professional Practice and Guidelines Committee. Carrier screening for spinal muscular atrophy. Genet Med 2008;10:840-842.

13. Gross SJ, Pletcher BA, Monaghan KG; Professional Practice and Guidelines Committee. Carrier screening in individuals of Ashkenazi Jewish descent. Genet Med 2008; 10:54-56.

14. Watson MS, Cutting GR, Desnick RJ, et al. Cystic fibrosis population carrier screening: 2004 revision of American College of Medical Genetics mutation panel. Genet Med 2004;6:387-391.

15. Pletcher BA, Bocian M; American College of Medical Genetics. Preconception and prenatal testing of biologic fathers for carrier status. Genet Med 2006;8:134-135.

16. Berg JS, Amendola LM, Eng C, et al.; Members of the CSER Actionability and Return of Results Working Group. Processes and preliminary outputs for identification of actionable genes as incidental findings in genomic sequence data in the Clinical Sequencing Exploratory Research Consortium. Genet Med 2013;15:860-867.

17. Wienke S, Brown K, Farmer M, Strange C. Expanded carrier screening panelsdoes bigger mean better? J Community Genet 2014;5:191-198.
18. Edwards JG, Feldman G, Goldberg J, et al. Expanded carrier screening in reproductive medicine-points to consider: a joint statement of the American College of Medical Genetics and Genomics, American College of Obstetricians and Gynecologists, National Society of Genetic Counselors, Perinatal Quality Foundation, and Society for Maternal-Fetal Medicine. Obstet Gynecol 2015;125:653-662.

19. Schneider JL, Goddard KA, Davis J, et al. "Is It Worth Knowing?" focus group participants' perceived utility of genomic preconception carrier screening. J Genet Couns 2016;25:135-145.

20. Wertz DC, Knoppers BM. Serious genetic disorders: can or should they be defined? Am J Med Genet 2002;108:29-35.

21. Rehm HL, Berg JS, Brooks LD, et al.; ClinGen. ClinGen-the clinical genome resource. N Engl J Med 2015;372:2235-2242.

22. National Society of Genetic Counselors. Prenatal testing for adult-onset conditions. 2014. http://nsgc.org/p/bl/et/blogaid=259. Accessed 03 March 2016.

23. Sénécal K, Rahimzadeh $V$, Knoppers BM, Fernandez $C V$, Avard D, Sinnett D. Statement of principles on the return of research results and incidental findings in paediatric research: a multi-site consultative process. Genome 2015;58: 541-548.

24. Jarvik GP, Amendola LM, Berg JS, et al.; eMERGE Act-ROR Committee and CERC Committee; CSER Act-ROR Working Group. Return of genomic results to research participants: the floor, the ceiling, and the choices in between. Am J Hum Genet 2014;94:818-826.

25. Lazarin GA, Detweiler S, Nazareth SB, Ashkinadze E. Genetic counselors' perspectives and practices regarding expanded carrier screening after initial clinical availability. J Genet Couns 2016;25:395-404

(1) () () This work is licensed under a Creative Commons Attribution-NonCommercial-NoDerivs $\quad 4.0$ International License. The images or other third party material in this article are included in the article's Creative Commons license, unless indicated otherwise in the credit line; if the material is not included under the Creative Commons license, users will need to obtain permission from the license holder to reproduce the material. To view a copy of this license, visit http://creativecommons.org/licenses/bync-nd/4.0/

(C) The Author(s) (2016) 